\title{
Response of Specific Leaf Area to a Large-Scale Environmental Gradient in Five Forest Types in China
}

\author{
Shiming ZHU, Xiaoli HOU, Li XUE* \\ College of Forestry, South China Agricultural University, Guangzhou, 510642, China
}

\begin{abstract}
Understanding the response of plant traits to environmental change is critical. Specific leaf area (SLA) is an important plant functional trait, correlating with environmental conditions and indicating certain ecophysiological traits. Although the SLA-environment relationship has been extensively studied, SLA response at the regional scale is limited. In order to study how SLA changes with environment at the regional scale, SLA and abiotic data were collected from five forest types distributed across 746 sites. These data were collected from studies examining the effect on SLA to temperature, precipitation and altitudinal variation. The mean SLA was $149 \pm 18,100 \pm 7,151 \pm 17,154 \pm 22$ and $113 \pm 25 \mathrm{~cm}^{2} \mathrm{~g}^{-1}$ in Boreal/temperate Larix forest (TLF), boreal/alpine Picea-Abies forest (APAF), temperate/subtropical montane Populus-Betula deciduous forest (MPBF), temperate deciduous broadleaf forest (TDBF) and subtropical evergreen broadleaf forest (SEBF), respectively. With increasing mean annual temperature (MAT), SLA increased significantly in TLF and SEBF, but decreased significantly in APAF and MPBF. As mean annual precipitation (MAP) increased, SLA significantly increased in TLF and significantly decreased in TDBF. A significant negative correlation occurred between SLA and altitude in APAF, TDBF and SEBF. These results indicated that SLA may predict tree response to environmental change in some forest types.
\end{abstract}

KEYWORD: altitude; environmental change; precipitation; phenotypic plasticity; SLA; temperature.

\section{INSTRUCTION}

Earth has recently experienced profound environmental change from rising mean global temperatures and changes in precipitation patterns (IPCC 2007; Wu et al. 2011) potentially affecting plants. Plants can adapt and tolerate relatively large environmental changes (Knight \& Ackerly 2003), their phenotypic plasticity tolerates rapid and flexible adjustment to environmental change (Sultan 2000). Understanding the effects of environmental factors on phenotypic expression is crucial for predicting plant response in real time to environmental change (Hudson et al. 2011).

One strategy for plants to adjust to changes in environmental conditions is to modify their leaf morphology (Niinemets 2001, Wright et al. 2004). A key leaf trait is specific leaf area (SLA, leaf area per unit dry mass), which quantifies light capture and $\mathrm{CO}_{2}$ assimilation capacity (Wei et al. 2011). Substantial intraspecific variation in SLA is common, often correlating with temperature and water availability (Poorter et al. 2009). The phenotypic plasticity of SLA has important implications for the survival probability of plant populations under changing environmental conditions (Scheepens et al. 2010). SLA has become increasingly popular for characterizing vegetation responses to environmental variation (e.g. Warren et al. 2006, Milla et al. 2008, Martin \& Asner 2009, Scheepens et al. 2010, Wei et al. 2011). Previous work indicated that SLA usually decreases with increasing altitude (Milla 2009), probably responding to decreasing temperature (Körner 2003a), or changes in water availability (Poorter et al. 2009). Plant species occurring in more stressful environments have smaller, thicker leaves and exhibit lower SLA (Knight \& Ackerly 2003). The SLA-environment relationship has been studied extensively (e.g. Scheepens et al. 2010, Wei et al. 2011), but the response of SLA at the regional scale is unclear (Milla et al. 2008). Uncertainty exists if the strategy shift in SLA is caused by environmental change as both these factors vary within and across plant species (Garnier et al. 2004, Li et al. 2005, Luo et al. 2005, Wei et al. 2011). Elucidating this relationship is required to advance our understanding of ecosystem function and environmental change. 
In China forests cover a large geographic area. The forest environments are characterized by steep temperature, precipitation and altitudinal gradients, providing ideal conditions to examine shifts in SLA across environmental gradients. To investigate a forest-level shift in plant SLA across different environments, we tested if the SLA in five different forest types shifted relative to changes in temperature, precipitation and altitude.

\section{MATERIALS AND METHODS}

\subsection{Dataset}

We compiled an SLA dataset $(n=746)$ from Luo's (1996) database $(n=685)$. These data included five major forest types in China: Boreal/temperate Larix forest (TLF), boreal/alpine Picea-Abies forest (APAF), temperate/subtropical montane PopulusBetula deciduous forest (MPBF), temperate deciduous broadleaf forest (TDBF) and subtropical evergreen broadleaf forest (SEBF).

These are typical forest types that occur from northern to southern China (Luo 1996). For each selected data point we collected data on: latitude, longitude, altitude, mean annual temperature (MAT), precipitation (MAP) and biome type. We recorded the geographic range and climate for each forest type (Table 1).

Table 1. Geographic and climatic ranges for the five forest types in data

\begin{tabular}{|l|c|c|l|l|c|c|}
\hline Forest type & Latitude $\left({ }^{\circ} \mathrm{N}\right)$ & Longitude $\left({ }^{\circ} \mathrm{E}\right)$ & $\begin{array}{l}\text { Altitude } \\
(\mathrm{m})\end{array}$ & $\begin{array}{l}\text { Mean annual } \\
\text { temperature }\left({ }^{\circ} \mathrm{C}\right)\end{array}$ & $\begin{array}{l}\text { Mean annual potential } \\
\text { evapotranspiration }(\mathrm{mm})\end{array}$ & $\begin{array}{l}\text { Mean } \\
\text { precipitation }(\mathrm{mm})\end{array}$ \\
\hline TLF & $28.62-52.60$ & $86.40-131.80$ & $441-4240$ & $-6.2-12.9$ & $340-522$ & $357-1274$ \\
\hline APAF & $26.14-52.60$ & $81.10-131.80$ & $410-4200$ & $-6.6-13.9$ & $329-739$ & $370-1937$ \\
\hline MPBF & $25.75-52.50$ & $85.20-134.00$ & $150-3640$ & $-5.5-16.0$ & $358-940$ & $241-1283$ \\
\hline TDBF & $28.25-51.70$ & $103.00-134.00$ & $177-2600$ & $-3.3-18.6$ & $429-926$ & $410-1142$ \\
\hline SEBF & $20.70-30.25$ & $85.20-120.17$ & $80-4160$ & $3.5-25.4$ & $386-1132$ & $637-2323$ \\
\hline
\end{tabular}

\subsection{Data analysis}

The slope and intercept of the regressions, SLAMAT, SLA-MAP and SLA-altitude relationships were estimated using the standardized major axis regression of the data (SMATR software Version 2.0, Falster et al., 2006, Warton et al. 2006).

\section{RESULTS}

The mean SLA values in the five forest types ranged from 129-188, 89-116, 125-172, 112-239 and 74$268 \mathrm{~cm}^{2} \mathrm{~g}^{-1}$ (TLF, APAF, MPBF, TDBF and SEBF, respectively). The differences within-forest type was relatively small in TLF (1.5 times), APAF (1.3 times) and MPBF (1.4 times) and relatively large in TDBF
(2.1 times) and SEBF (3.6 times). The mean SLA was high in TLF, MPBF and TDBF $(149 \pm 18$, $151 \pm 17$ and $154 \pm 22 \mathrm{~cm}^{2} \mathrm{~g}^{-1}$, respectively) and low in APAF and SEBF $\left(100 \pm 7\right.$ and $113 \pm 25 \mathrm{~cm}^{2} \mathrm{~g}^{-1}$, respectively).

The relationship between SLA and MAT was significantly positive in TLF and SEBF and significantly negative in APAF and MPBF $(P$ $\leq 0.041$, Table 2). SLA showed a significant positive correlation with MAP in TLF and a significant negative correlation with MAP in TDBF $(P$ $\leq 0.008)$. SLA significantly decreased in APAF, TDBF and SEBF with increasing altitude $(P \leq$ $0.001)$. There was no correlation with SLA in TLF and MPBF. 
Table 2. Standardized major axis regression (SMA) slopes and y-intercepts ( $\square$ SMA and $\square$ SMA, respectively) for data of SLA (cm ${ }^{2}$ $\mathrm{g}^{-1}$ ) and mean annual temperature (MAT) $\left({ }^{\circ} \mathrm{C}\right)$, mean annual precipitation (MAP) (mm) and altitude (m). Data, grouped according to forest types, taken from Luo (1996).

\begin{tabular}{|c|c|c|c|c|c|c|}
\hline Forest type & Environmental factor & RMA $(95 \%$ CI $)$ & RMA $(95 \% \mathrm{CI})$ & $n$ & $R^{2}$ & $P$ \\
\hline \multirow[t]{3}{*}{ TLF } & MAT & $6.2820(4.9570,7.9630)$ & $158.5(153.3,163.6)$ & 48 & 0.350 & $<0.001$ \\
\hline & MAP & $0.1011(0.0755,0.1354)$ & $88.6(69.3,108.0)$ & & 0.003 & 0.721 \\
\hline & altitude & $0.0198(0.0154,0.0254)$ & $121.5(112.8,130.1)$ & & 0.030 & 0.106 \\
\hline \multirow[t]{3}{*}{ APAF } & MAT & $-2.1450(-2.4870,-1.8510)$ & $108(106.4,109.7)$ & 168 & 0.063 & 0.001 \\
\hline & MAP & $-0.0253(-0.0289,-0.0220)$ & $121.0(118.0,124.0)$ & & 0.207 & $<0.001$ \\
\hline & altitude & $-0.0085(-0.0097,-0.0074)$ & $126.3(122.6,13.00)$ & & 0.189 & $<0.001$ \\
\hline \multirow[t]{3}{*}{ MPBF } & MAT & $-5.003(-5.943, \quad-4.212)$ & $170.7(165.6,175.8)$ & 127 & 0.045 & 0.017 \\
\hline & MAP & $-0.0965(-0.1150,-0.0810)$ & $214.6(202.7,226.5)$ & & 0.014 & 0.188 \\
\hline & altitude & $0.0204(0.0172,0.0244)$ & $118.7(111.8,125.7)$ & & 0.009 & 0.279 \\
\hline \multirow[t]{3}{*}{ TDBF } & MAT & $-9.1180(-10.6310,-7.820)$ & $207.6(198.1,217.2)$ & 165 & 0.007 & 0.301 \\
\hline & MAP & $0.2355(0.2025,0.2738)$ & $1.7(-21.7,25.1)$ & & 0.042 & 0.008 \\
\hline & altitude & $-0.0453(-0.0520,-0.0395)$ & $213.8(204.7,222.9)$ & & 0.200 & $<0.001$ \\
\hline \multirow[t]{3}{*}{ SEBF } & MAT & $8.5250(7.5100,9.6780)$ & $-13.9(-30.6,2.7)$ & 238 & 0.018 & 0.041 \\
\hline & MAP & $0.0834(0.0735,0.0948)$ & $-4.5(-20.1,11.1)$ & & 0.009 & 0.136 \\
\hline & altitude & $-0.0318(-0.0361,-0.028)$ & $149.7(143.6,155.8)$ & & 0.048 & 0.001 \\
\hline
\end{tabular}

\section{DISCUSSION}

Temperature is a key driver to variation in SLA in TLF, SEBF, APAF and MPBF. SLA showed a significant positive association increases with increasing MAT in TLF and SEBF, suggesting temperature regulation (Scheepens et al. 2010). Increasing SLA is probably a response to increasing temperatures among and within plant species (Körner 2003b). The increase in SLA can be realized through a decrease in leaf density and thickness (Atkin et al. 2006, Poorter et al. 2009). The decrease in leaf density occurs when expanding cell expansion, which leads to larger cells and less cells per unit leaf volume, while the decrease in thickness occurs from a reduction in the number of palisade parenchyma layers (Poorter et al. 2009). However, APAF and MPBF SLA showed the opposite response, i.e., their SLA significantly decreased with increasing temperature. This response is because leaves with lower SLA can better withstand and recover their photosynthetic capacity following exposure to high temperatures compared with species having higher SLA. Moreover, temperature and precipitation are often negatively correlated, with lower precipitation in warmer environments (Knight \& Ackerly 2003). The negative correlation between temperature and precipitation may explain why SLA decreased in APAF and MPBF.

SLA significantly increased with increasing MAP in TDBF, supporting other studies (e.g., Raich et al. 1997, Wang \& Gao 2004, Wright et al. 2005). Plants may produce leaves with higher SLA in environments with greater water availability because enhanced water use efficiency is associated with increased photosynthetic tissue relative to transpiration area (Fonseca et al., 2000, Wright et al., 2001), suggesting a link between SLA and photosynthetic performance (Knight \& Ackerly 2003).

SLA commonly decreases with reduced rainfall (Schulze et al. 2006, Warren et al. 2006). Under drought stress, lower SLA indicates thicker or more dense leaves, conferring drought tolerance as those leaves have a higher proportion of their mass in cell wall tissue, with the ability to withstand lower water potentials (Martinez et al. 2007, Cano et al. 2008, Mitchell et al. 2008, Walls 2010). Plants in TDBF appeared to respond to drought using similar mechanisms, with lower SLA reducing water loss (Fernández \& Reynolds 2000), enabling the trees to overcome prolonged drought. In contrast, SLA was significantly higher with increasing MAP in APAF. Some researchers (e.g., Chabot \& Hicks 1982) found that sclerophylly with low SLA, occurred in some high-rainfall environments (e.g. wetlands), possibly 
an adaptation to infertile-soil because soil is an important factor controlling leaf traits (Ordoñez et al. 2009). APAF occur at relatively high altitudes, resulting in poor soil fertility where low nutrient levels may be important in favoring a low SLA (Turner 1994, Fonseca et al. 2000). Moreover, high precipitation often accompanies low temperature in mountain forests, potentially reducing SLA.

SLA evolved between plants and their environment to minimize the negative influence of harsh conditions (Meng et al. 2007). Altitude broadly influences plant species and environmental factors (Ma et al. 2010). Cordell et al. (1998) found that SLA of Metrosideros polymorpha decreased significantly with increasing elevation. Körner (2003b) found a decrease in SLA with increasing elevation resulting from leaf/needle size becoming smaller but thicker (Pan et al. 2009). Similarly, our study found that SLA significantly decreased with altitude in APAF, TDBF and SEBF. Ma et al. (2010) demonstrated that SLA was closely associated with photosynthetic capacity. Decreasing SLA with increasing altitude was realized through an increase in leaf density and thickness (Atkin et al. 2006, Poorter et al. 2009). We suggest that these changes are an investment in photosynthetically active tissue, promoting leaf efficiency in light capture (Körner 2003b, Scheepens et al. 2010). Moreover, increasing photon flux density from reduced cloud cover during the growing season at higher altitude could be a complementary mechanism of low SLA of trees at high altitudes (Milla 2009).

\section{ACKNOWLEDGMENTS}

We're grateful that Dr. Luo provided the precious information for our study. This research was partially supported by Foundation of Guangdong Forestry Bureau (No. 4400-F11031, 4400-F11055).

\section{REFERENCES}

[1] Atkin, O. K., Loveys, B. R., Atkinson, L. J. \& Pons, T.L. 2006. Phenotypic plasticity and growth temperature: understanding interspecific variability. Journal of Experimental Botany 57: 267-281.

[2] Cano, L. J., Fleck, E. I., Blanco-Moreno, J. M. \& Sans, F. 2008. Increased fitness and plasticity of an invasive species in its introduced range: a study using Senecio pterophorus. Journal of Ecology 96: 468-476.

[3] Chabot, B. F. \& Hicks, D. J. 1982. The ecology of leaf life spans. Annual Review of Ecology, Evolution, and Systematics 13: 229-259.

[4] Cordell, S., Goldstein, G., Muleller-Dombois, D., Webb, D. \& Vitousek, P.M. 1998. Physiological and morphological variation in Metrosideros polymorpha, a dominant Hawaiian tree species, along an altitudinal gradient: role of phonotypic plasticity. Oecologia 113: 188-196.

[5] Falster, D., Warton, D. \& Wright, I. 2006. User's guide to SMATR: standardised major axis tests and routines version 2.0, copyright 2006. Available at: http: //www.bio.mq.edu.au/ecology/SMATR/.

[6] Fernández, R. J. \& Reynolds, J. F. 2000. Potential growth and drought tolerance of eight desert grasses: lack of a trade-off? Oecologia 123: 90-98.

[7] Fonseca, C. R., McC Overton, J., Collins, B. \& Westoby, M. 2000. Shifts in trait-combinations along rainfall and phosphorus gradients. Journal of Ecology 88: 964-977.

[8] Garnier, E., Cortez, J., Billes, G., Navas, M. L., Roumet, C., Debussche, M., Laurent, G., Blanchard, A., Aubry, D., Bellmann, A., Neill, C. \& Toussaint, J. P. 2004. Plant functional markers capture ecosystem properties during secondary succession. Ecology 85: 2630-2637.

[9] Hudson, J. M. G., Henry, G. H. R. \& Cornwell, W.K. 2011. Taller and larger: shifts in Arctic tundra leaf traits after 16 years of experimental warming. Global Change Biology 17: 1013-1021.

[10] Intergovernmental Panel on Climate Change (IPCC). 2007. Climate change 2007: the physical science basis summary for policy makers. Contribution of Working Group I to the Fourth Assessment Report of the Intergovernmental Panel on Climate Change. IPCC WGI 4th Assessment Report.

[11] Knight, C. A. \& Ackerly, D. D. 2003. Evolution and plasticity of photosynthetic thermal tolerance, specific leaf area and leaf size: congeneric species from desert and coastal environments. New Phytologist 160: 337-347.

[12] Körner, C. 2003a. Alpine plant life, 2nd edn. Heidelberg: Springer.

[13] Körner, C. 2003b. Carbon limitation in trees, Journal of Ecology 91: 4-17.

[14] Li, Y. H., Luo, T.X., Lu, Q., Tian, X. Y., Wu, B. \& Yang, H.H. 2005. Comparisons of leaf traits among 17 major plant species in Shazhuyu sand control experimental station of Qinghai Province. Acta Ecologica Sinica 25: 994-999.

[15] Luo, T. X. 1996. Patterns of net primary productivity for Chinese major forest types and their mathematical models. Ph. D. Dissertation. Beijing: Chinese Academy of Sciences.

[16] Luo, T. X., Luo, J. \& Pan, Y. 2005. Leaf traits and associated ecosystem characteristics across subtropical and timberline forests in the Gongga Mountains, eastern Tibetan Plateau. Oecologia 142: 261-273.

[17] Ma, W. L., Shi, P. L, Li, W. H., He, Y. T., Zhang, X. Z., Shen, Z. X. \& Chai, S. Y. 2010. Changes in individual plant traits and biomass allocation in alpine meadow with elevation variation on the Qinghai-Tibetan Plateau. Science China Life Sciences 53: 1142-1151.

[18] Martin, R. E. \& Asner, G. P. 2009. Leaf chemical and optical properties of Metrosideros polymorpha across environmental gradients in Hawaii. Biotropica 41 (3): 292-301.

[19] Martinez, J. P., Silva, H., Ledent, J. F. \& Pinto, M. 2007. Effect of drought stress on the osmotic adjustment, cell wall elasticity and cell volume of six cultivars of common beans (Phaseolus vulgaris L.). Journal of Agronomy 26: 30-38. 
[20] Meng, T. T., Ni, J. \& Wang, G. H. 2007. Plant functional traits, environments and ecosystem functioning. Journal of Plant Ecology 31: 150-165.

[21] Milla, R. 2009. The leafing intensity premium hypothesis tested across clades, growth forms and altitudes. Journal of Ecology 97: 972-983.

[22] Milla, R., Reich, P. B., Niinemets, Ü. \& Castro-Díez, P. 2008. Environmental and developmental controls on specific leaf area are little modified by leaf allometry. Functional Ecology 22: 565-576.

[23] Mitchell, P., Veneklaas, E., Lambers, H. \& Burgess, S. 2008. Using multiple trait associations to define hydraulic functional types in plant communities of south-western Australia. Oecologia 158: 385-397.

[24] Niinemets, Ü. 2001. Global-scale climatic controls of leaf dry mass per area, density, and thickness in trees and shrubs. Ecology 82:453-469.

[25] Ordoñez, J.C., van Bodegom, P. M., Witte, J. M., Wright, I. J., Reich, P. B. \& Aerts, R. 2009. A global study of relationships between leaf traits, climate and soil measures of nutrient fertility. Global Ecology and Biogeography 18: 137-149.

[26] Pan, H. L., Liu, X.L., Cai, X. H., Du, Z., He, F., Wang, L., Jia, C. \& Li, M. H. 2009. Growth and morphological responses of Fargesia angustissima to altitude in the Wolong Nature Reserve, southwestern China. Acta Ecologica Sinica 29: 144-149.

[27] Poorter, H., Niinemets, Ü., Poorter, L., Wright, I. J. \& Villar, R. 2009. Causes and consequences of variation in leaf mass per area (LMA): a meta-analysis. New Phytologist 182 : 565-588.

[28] Raich, J. W., Russell, A. E. \& Vitousek, P. M. 1997. Primary productivity and ecosystem development along an elevational gradient on Mauna Loa, Hawaii, Ecology $78: 707-721$.

[29] Scheepens, J. F., Frei, E. S. \& Stöcklin, J. 2010. Genotypic and environmental variation in specific leaf area in a widespread Alpine plant after transplantation to different altitudes. Oecologia 164: 141-150.

[30] Schulze, E. D., Turner, N. C., Nicolle, D. \& Schumacher, J. 2006. Leaf and wood carbon isotope ratios, specific leaf areas and wood growth of Eucalyptus species across a rainfall gradient in Australia. Tree Physiology 26, 479492.

[31] Sultan, S. 2000. Phenotypic plasticity for plant development, function and life history. Trends in Plant Science 5 : 537-542.
[32] Turner, I. M. 1994. Sclerophylly: primarily protective? Functional Ecology 8: 669-675.

[33] Walls, R. L. 2010. Hybridization and plasticity contribute to difference among coastal and wetland populations of invasive hybrid Japanese Knotweed s. l. (Fallopia spp.). Estuaries and Coasts 33: 902-918.

[34] Wang, R. Z. \& Gao, Q. 2004. Morphological responses of Leymus chinensis (Poaceae) to the large-scale climatic gradient along the North-east China Transect (NECT). Diversity and Distributions 10: 65-73.

[35] Warren, C. R., Dreyer, E., Tausz, M. \& Adams, M. A. 2006. Ecotype adaptation and acclimation of leaf traits to rainfall in 29 species of 16-year-old Eucalyptus at two common gardens. Functional Ecology 20: 929-940.

[36] Warton, D. I., Wright, I. J., Falster, D. S. \& Westoby, M. 2006. Bivariate line-fitting methods for allometry. Biological Reviews 81: 259-291.

[37] Wei, H., Wu, B., Yang, W. \& Luo, T. 2011. Low rainfallinduced shift in leaf trait relationship within species along a semi-arid sandy land transect in northern China. Plant Biology 13: 85-92.

[38] Wright, I. J., Reich, P. B., Cornelissen, J. H. C., Falster. D., Groom, P. K., Hikosaka, K., Lee, W., Lusk, C. H., Niinemets, U., Oleksyn J., Osada, N., Poorter, H., Warton, D. \& Westoby, M. 2005. Modulation of leaf economic traits and trait relationships by climate. Global Ecology and Biogeography 14: 411-421.

[39] Wright, I. J., Reich, P. B., Westoby, M., Ackerly, D.D., Baruch, Z., Bongers, F., Cavender-Bares, J., Chapin, T., Cornelissen, J. H. C., Diemer, M., Flexas, J., Garnier, E., Groom, P.K., Gulias, J., Hikosaka, K., Lamont, B.B., Lee, T., Lee, W., Lusk, C., Midgley, J.J., Navas, M.L., Niinemets, Ü., Oleksyn, J., Osada, N., Poorter, H., Poot, P., Prior, L., Pyankov, V.I., Roumet, C., Thomas, S.C., Tjoelker, M.G., Veneklaas, E.J. \& Villar, R. 2004. The worldwide leaf economics spectrum. Nature 428: 821827.

[40] Wright, I. J., Reich, P. B. \& Westoby, M. 2001. Strategy shifts in leaf physiology, structure and nutrient content between species of high and low rainfall and high and low nutrient habitats. Functional Ecology 15: 423-434.

[41] Wu, Z. T., Kstra, P. D., Koch, G. W., Peñuelas, J. \& Hungate, B. A. 2011. Responses of terrestrial ecosystems to temperature and precipitation change: a meta-analysis of experimental manipulation. Global Change Biology 17: 927-942. 